\title{
Crónica de viagem: um espectáculo dos Elevator Repair Service e outras experiências off
}

ANA PAIS

Título: Fondly, Collette Richland. Texto: Collette Richland. Autor: Sibyl Kempson. Encenação: John Collins. Criação colectiva: Elevator Repair Service. Interpretação: Lindsay Hockaday, Kate Benson, Maggie Hoffman, April Matthis, Ben Williams, Susie Sokol. Produção: Elevator Repair Service e New York Theatre Workshop. Local e data de estreia: Nova lorque, New York Theatre Workshop, 11 de Setembro de 2015.

Título: The Alcoholic Movie Musical! Espectáculo: Cynthia Hopkins. Vídeo: Jeff Sugg. Interpretação: Cynthia Hopkins. Local e data de estreia: Nova lorque, Bushwick Starr, 7 de Outubro de 2015.

Título: Bronx Gothic. Autor, interpretação e desenho de som: Okwui Okpokwasili. Direcção, cenografia e sonoplastia: Peter Born. Local e data de estreia: Nova lorque, PS 122 Theater, 2014.

Em Nova Iorque, diversidade e abundância são um problema. Decidir o que ver numa única semana pode ser tarefa extenuante. Isto na teoria porque, na prática, o preço dos bilhetes e o tipo de espectáculo em que estamos interessados tornam rapidamente a escolha mais fácil. Para quem, como eu, está mais interessado num trabalho de pesquisa experimental (que hoje em dia já nem se pode considerar off-off-Broadway mas off-Manhattan), tudo se simplifica - ou não. Se não estivermos a par dos circuitos alternativos, pode ser tão difícil como encontrar uma agulha num palheiro. É para isso que servem os amigos e colegas. Em Nova Iorque, diversidade e abundância são o benefício de uma cidade que produz nichos de interesse hiper-especializados em que cada um se move.

Dentro do nicho alternativo do teatro e da performance art, há espaços mais ou menos institucionalizados. Grandes centros culturais como o Public Theatre (Baixa de Manhattan) ou o BAM (Brooklyn) têm uma programação que inclui trabalhos experimentais, embora depois de passar o crivo do reconhecimento. Outros espaços como a Chocolate Factory (Queens), o PS122 (ainda em obras), o Abrons Art Center, o New York Live Arts, o New York Theatre Workshop ou os míticos The Kitchen, La Mamma e o Westbeth (onde Merce Cunningham tinha o seu estúdio) ocupam 


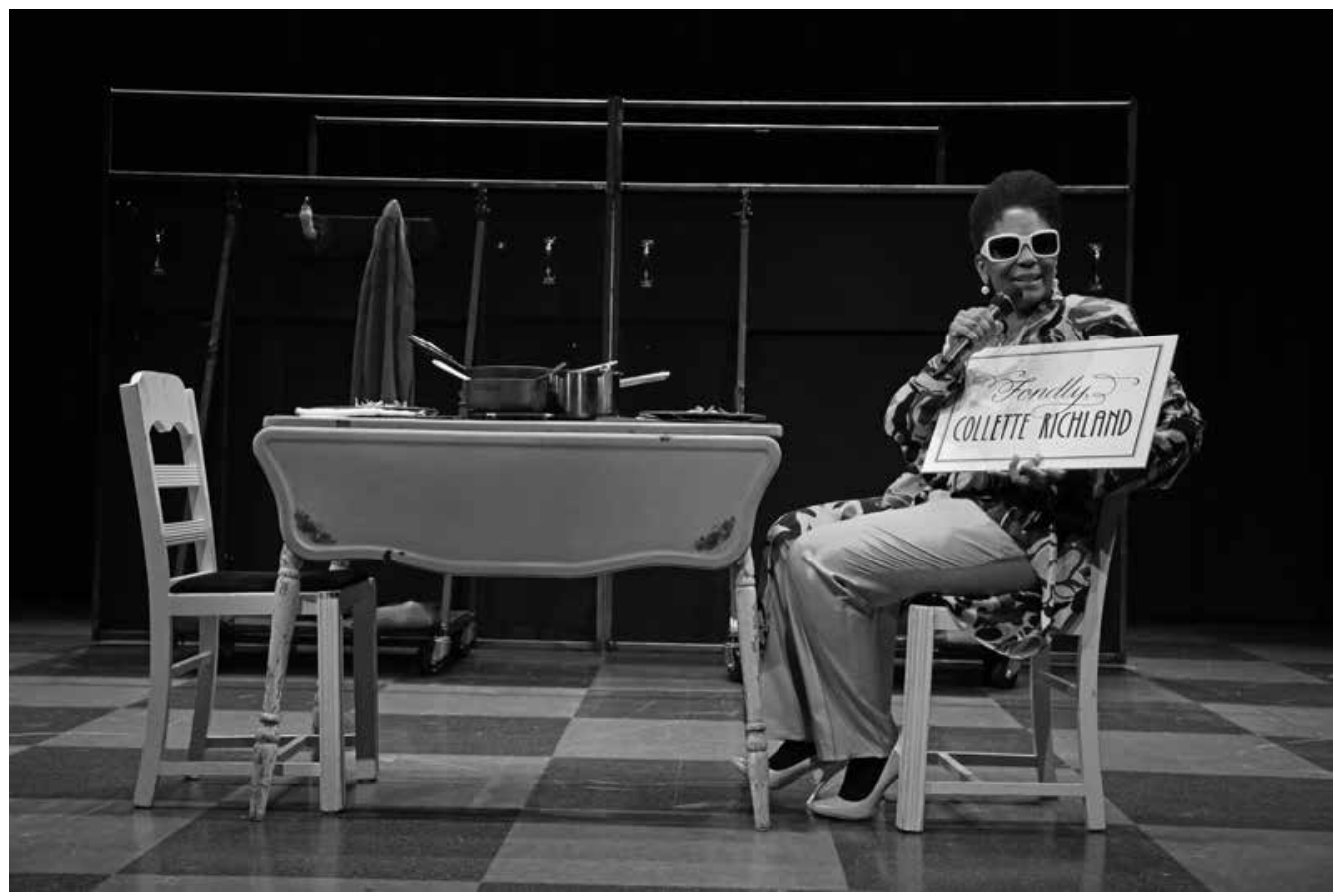

FONDLY, COLLETTE RICHLAND, DE SIBYL KEMPSON, ELEVATOR REPAIR SERVICE, 2015 (LINDSAY HOCKADAY, KATE BENSON, MAGGIE HOFFMAN, APRIL MATTHIS, BEN WILLIAMS, SUSIE SOKOL), [F] JOAN MARCUS

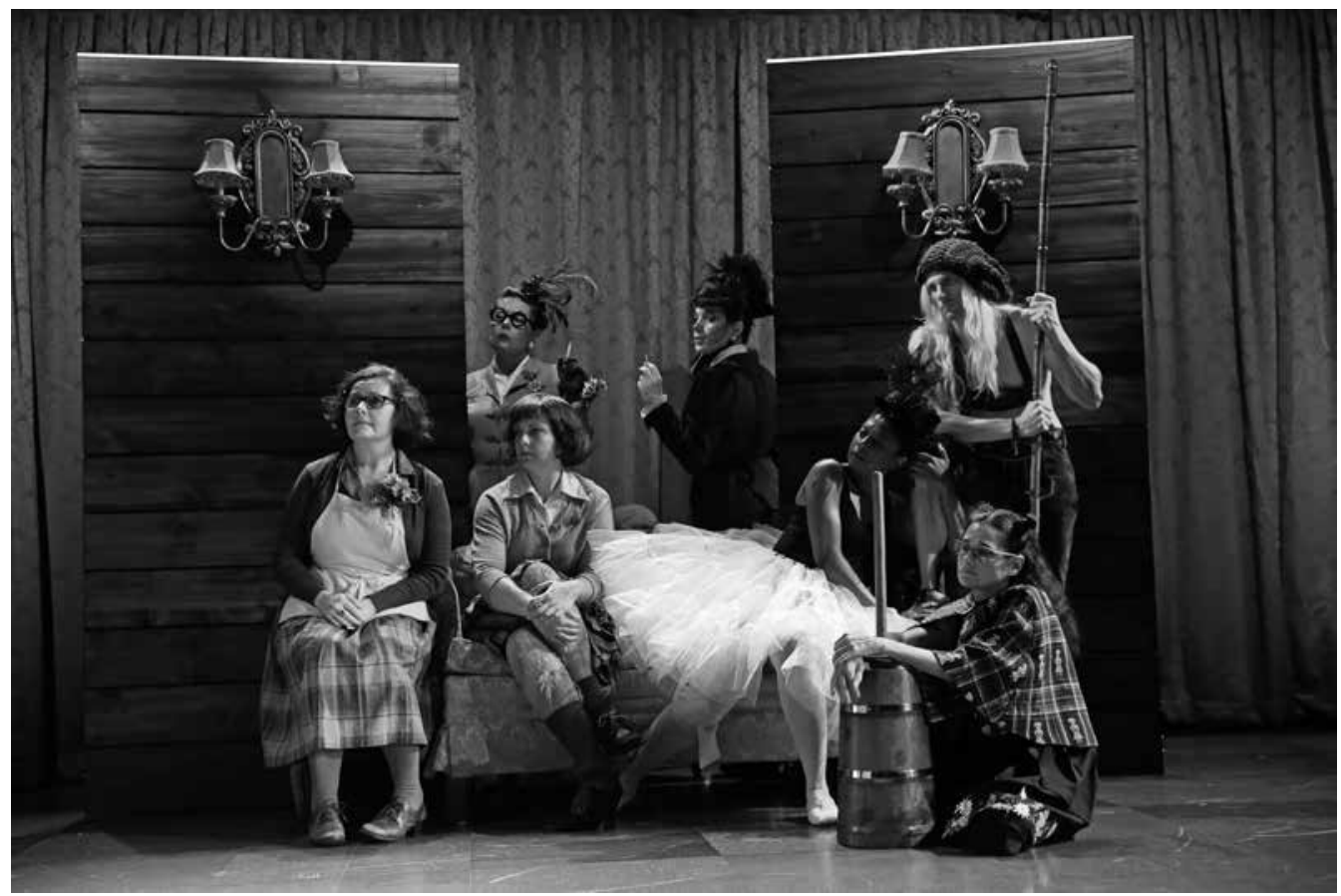

FONDLY, COLLETTE RICHLAND, DE SIBYL KEMPSON, ELEVATOR REPAIR SERVICE, 2015 (APRIL MATTHIS), [F] JOAN MARCUS 
uma zona de risco controlado, isto é, acolhem residências, festivais não comerciais e programam artistas nem sempre conhecidos, entrando em processo de legitimação com essa passagem.

Continuam a surgir outros pequenos espaços para produções e artistas emergentes, como é o caso do Bushwick Starr, na já muito gentrificada zona de estúdios de artistas em Bushwick, porque há sempre muitos que ficam de fora dos circuitos.

Foi no Bushwick Starr que vi, por recomendação de um amigo, o espectáculo The Alcoholic Movie Musical!, de e por Cynthia Hopkins. Artista de talentos múltiplos, Hopkins interpreta no piano e na guitarra as músicas e o texto que compôs num tom entre o irónico e o desajeitado que ajuda a criar uma figura titubeante, condicente com os estados produzidos pela adição sobre a qual nos quer falar na primeira pessoa: o alcoolismo. Mas nem por isso a actuação é frágil. Pelo contrário, o domínio de um tom performativo bem como das competências musicais é sólido e gera um produtivo diálogo com os vídeos de Jeff Sugg, cúmplice na cena e na vida, bem integrados na dramaturgia do espectáculo, quer do ponto de vista da narração quer do ponto de vista da adaptação ao espaço (a curadora que lhe encomenda o espectáculo aparece como sombra caricatural, representada por Hopkins, que se agiganta entre as janelas da sala). Hopkins transforma a superação pessoal do vício em tema de um filme musical - o espectáculo narra as etapas do projecto-, encontrando cenas que expõem a fragilidade com um imenso efeito cómico, sem perder uma estranha densidade. Por exemplo, no início do espectáculo, Hopkins ao piano repete as frases instrumentais de um tema enquanto a sua voz, em off, expressa divagações angustiantes sobre o fracasso que já antecipa e as inseguranças que a impedem de avançar. Mas avança, pela ficção, avança. Não fora o excessivo fechamento sobre si próprio, sobre o metadiscurso em torno das condições materiais do projecto em causa, o espectáculo teria sido uma surpresa sem senãos.

Outro trabalho com referências autobiográficas, igualmente apresentado por um casal, é o de Okwui Okpokwasili (com Peter Born na cenografia e na sonoplastia), performer e coreógrafa, que tem colaborado com Ralph Lemmon em diversos projectos. Embora tenha afirmado na conversa pós-espectáculo que os dados autobiográficos constituem apenas cinco por cento de Gothic Bronx, Okpokwasili interpreta a solo episódios de amizade e puberdade na vida de duas adolescentes do Bronx, bairro 


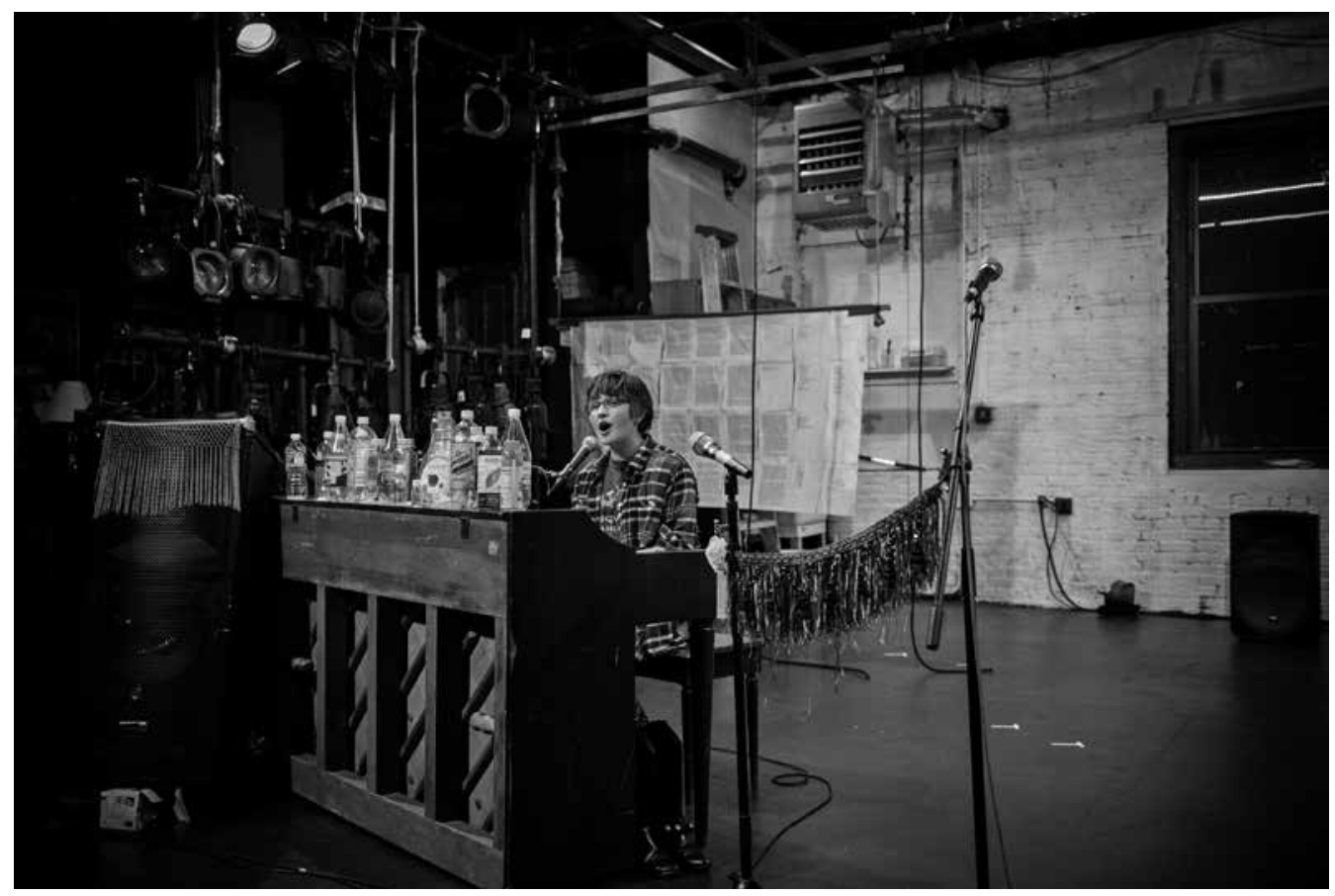

THE ALCOHOLIC MOVIE MUSICAL!, DE E POR CYNTHIA HOPKINS, 2015 (CYNTHIA HOPKINS), [F] DUSTIN DRANKOSKI

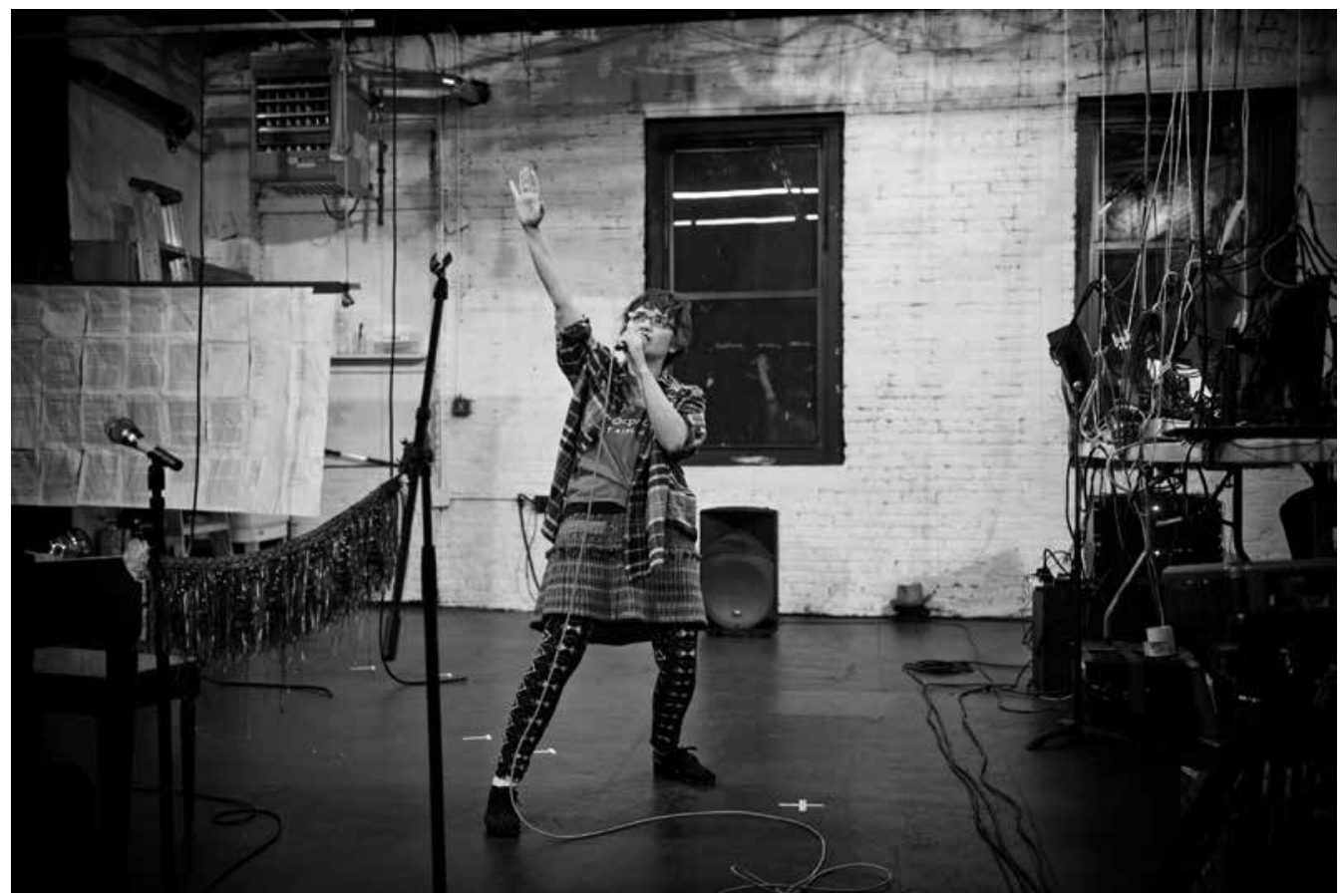

THE ALCOHOLIC MOVIE MUSICAL!, DE E POR CYNTHIA HOPKINS, 2015 (CYNTHIA HOPKINS), [F] DUSTIN DRANKOSKI 


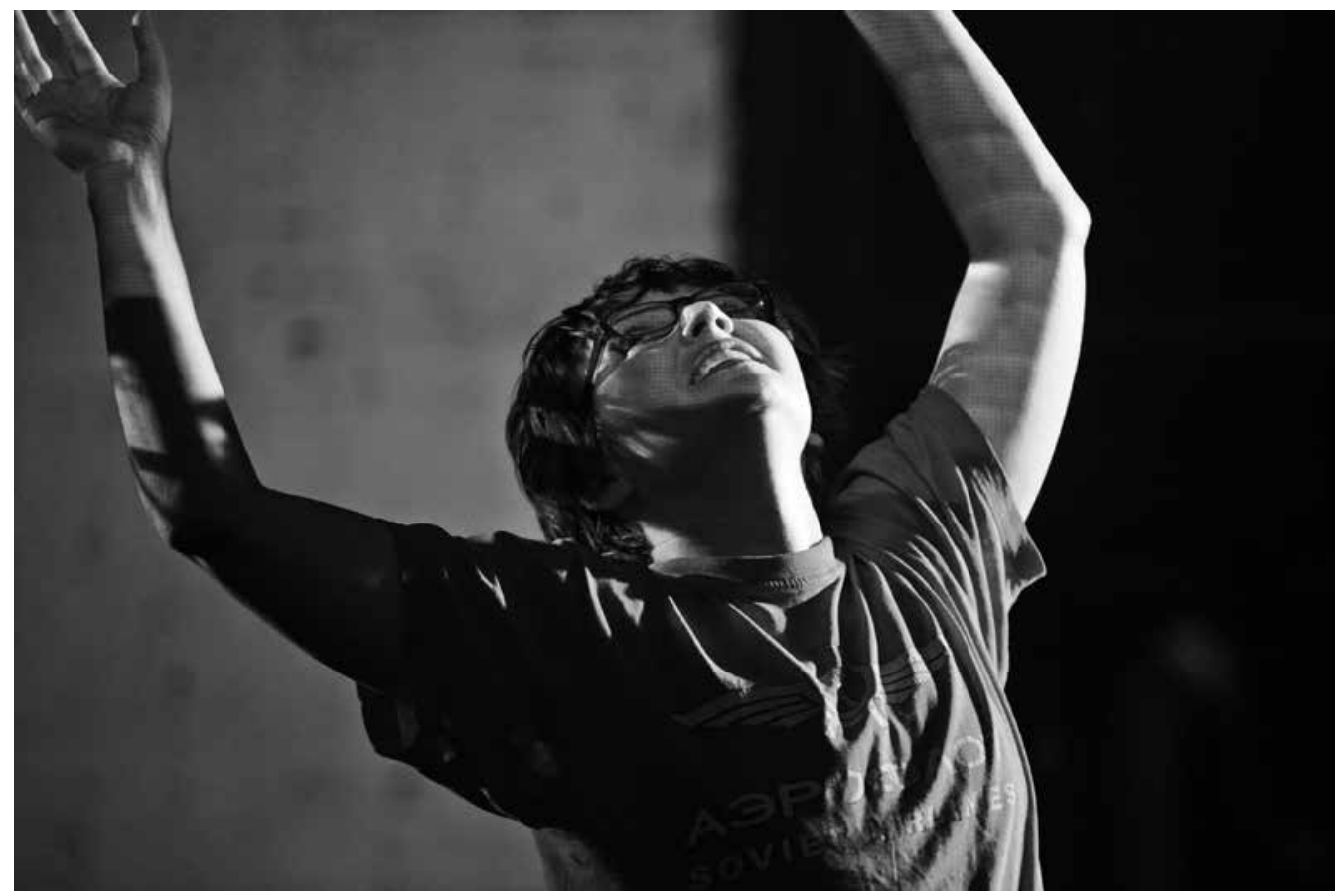

THE ALCOHOLIC MOVIE MUSICAL!, DE E POR CYNTHIA HOPKINS, 2015 (CYNTHIA HOPKINS), [F] DUSTIN DRANKOSKI

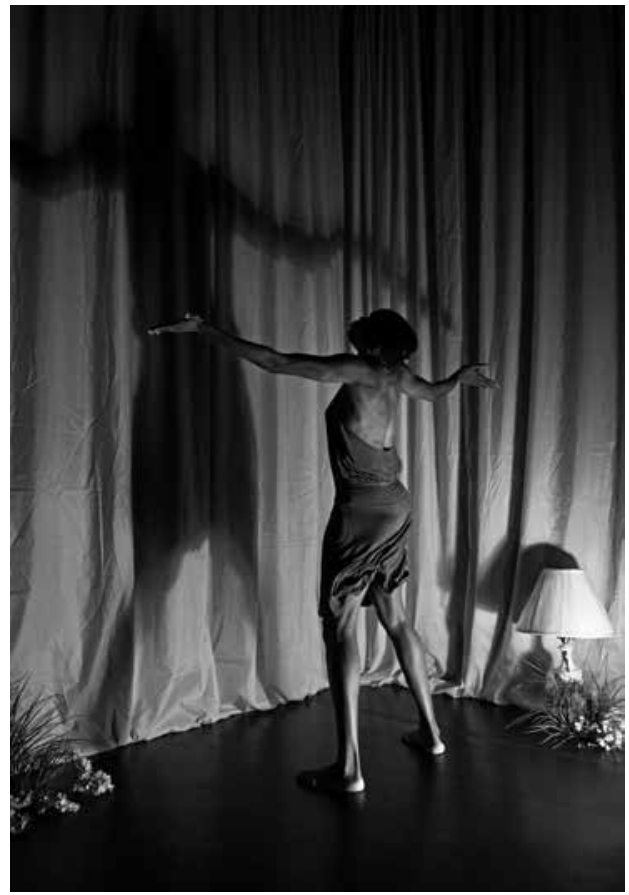

BRONX GOTHIC, DE E POR OKWUI OKPOKWASILI, 2014 (OKWUI OKPOKWASILI), [F] IAN DOUGLAS

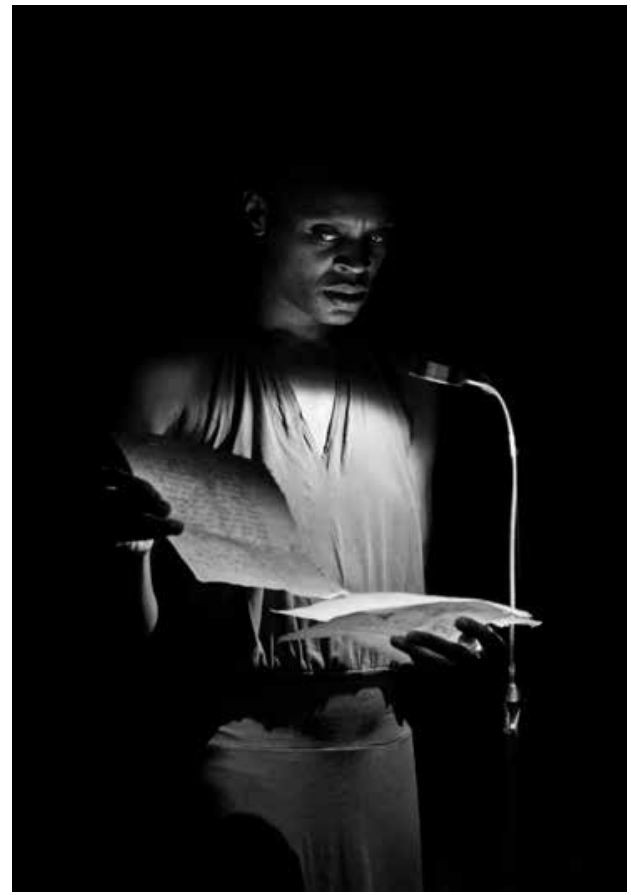

BRONX GOTHIC, DE E POR OKWUI OKPOKWASILI, 2014 (OKWUI OKPOKWASILI), [F] IAN DOUGLAS 
onde cresceu, filha de pais nigerianos, nos anos 80 . Tendo-se distinguido por um trabalho em que o carácter de instalação assume protagonismo, Okpokwasili dá corpo às vozes do texto de sua autoria num espaço cénico delimitado por cortinas brancas, com sacos de plástico branco pendurados (recordando o saco esvoaçante de Beleza Americana), flores de plástico, candeeiros e baldes espalhados. Através da voz pausada e do acentuado sotaque do bairro, Okpokwasili desenha figuras no ar - intensas, doridas e latejando hormonas; através do corpo esguio e vibrante, quebra a doçura e a agressividade das palavras com movimentos rebolados e repetidos entre o ritual iniciático e a partilha de afectos. Este é, de resto, o território do corpo criado ao longo de vinte minutos iniciais em que Okpokwasili, a um canto, repete uma coreografia sensual e enigmática. É ao passar por essa «experiência» de exaustão que a performer abre um tempo e um espaço para contar a história, um lugar onde o público é convidado a entrar também porque atravessa a experiência com ela - singular, tal como o espectáculo.

A maior expectativa estava reservada para a produção dos Elevator Repair Service, Fondly, Collette Richland, apresentado no New York Theatre Workshop. O título do espectáculo aponta para uma despedida carinhosa, embora protocolar. Podia ser o final de uma carta mas não é. É a fórmula de encerramento do programa de rádio da personagem Collette Richland, a mestre-de-cerimónias das histórias de transformação de que o texto de Sibyl Kempson trata. Como uma testemunha etérea dos acontecimentos dos quais se diz lembrar (mas não se lembra), Collette Richland invade a casa dos Fitzuberts através da voz, difundida pelo transmissor. Em cena, a sua presença marca o início, meio e fim do espectáculo. Ela simboliza a voz de antigos tempos matriarcais que reverbera como um chamamento para uma consciência do poder e do valor do feminino. Embora ainda necessário em termos de igualdade social, e portanto actual, este apelo surge de forma surpreendentemente baça e literal, num espectáculo em que a loucura e a ambiguidade não são suficientes para resolver aspectos formais da relação com o texto.

Um casal recebe uma visita de um local representative (figura dúbia, porém muito americana, entre um vendedor e um candidato ao poder local) à hora de jantar. Convidado a partilhar a refeição, o vendedor-candidato é igualmente convidado a atravessar uma pequena porta, onde lerá, com Mabrel, uma oração de uma 
Bíblia antiga. Escusado será dizer que, a partir deste momento de passagem - tal como em Alice -, começa uma fantástica viagem iniciática de todas as personagens. Na cena seguinte, estamos num hotel nos Alpes, perto de um lago famoso e do precipício Montieren Schwartz, território de personagens e vozes misteriosas, com direito a bruxas xamânicas e marinheiros de terra, fazendo ressurgir ideias de feminino que se imagina não conforme às leis patriarcais.

Como não será difícil de imaginar para quem conhece a trilogia de textos clássicos dos ERS, apresentada na Culturgest (Gatz, The Sound and The Fury, The Select), à medida que o espectáculo avança, adensa-se o disparate, o nonsense e as soluções cénicas que desobedecem a qualquer lógica, realista ou não. À diferença da trilogia, porém, neste espectáculo em que o texto é sublinhado pelo delírio cénico, não lhe resiste. Esta resistência do material literário ou, inversamente, o conflito que as soluções cénicas injectavam no fazer daqueles textos era, na minha opinião, fundamental para a estética dos ERS. Neste caso, o desvairo assinalável das soluções encontradas acaba por reforçar o texto, e não raro, ilustra-o. Uma amiga nova-iorquina conhecedora da companhia diz-me que este trabalho se aproxima da fase inicial dos ERS, que desconheço. Não sei se por isso ou se por esta ser a primeira vez que a companhia encena um texto dramático (de um autor vivo), Fondly, Collette Richland ficará, na minha memória, como um espectáculo intrigante, de passagem também ele para um outro espaço de investigação no percurso da companhia. 